\title{
Partiality and Retrospective Justification
}

\author{
Bernhard Salow, Trinity College Cambridge \\ Penultimate Draft - Please cite Published Version
}

\begin{abstract}
Sometimes changes in an agent's partial values can cast a positive light on an earlier action, which was wrong when it was performed. Based on independent reflections about the role of partiality in determining when blame is appropriate, I argue that in such cases the agent shouldn't feel remorse about her action and that others can't legitimately blame her for it, even though that action was wrong. The action thus receives a certain kind of retrospective justification.
\end{abstract}

Some decisions that look unjustified at the time start to look better when we assess them in retrospect. Often, this is merely because we later have access to information that wasn't available at the time. But in the more interesting cases, it is instead because 'what matters' seems different when we look back. Two potential examples (not necessarily equally convincing) include:

\section{Gauguin $^{2}$}

In the midst of a debilitating mid-life crisis, Gauguin abandons his family to move to Tahiti and pursue his painting hobby. At the time of action, painting really is just a hobby to him, something he does to fill his spare time; and so there is very little he can say in defence of his decision. However, when Gauguin starts pursuing this hobby full time, he turns out to be an extremely talented artist, and his decision ultimately allows him to live comfortably in an art-world he didn't even know existed, produce wonderful work, and find self-fulfilment in his new life. When he looks back at his decision later, then, he feels that, while harsh, it was ultimately a good one: the pursuit of art and self-fulfilment really is worth such sacrifices.

\footnotetext{
${ }^{1}$ A third well-known example is the decision not to have treatment that prevents or mitigates a disability early in life (such as a cochlear implant), since some disabled people find that many of their most valuable activities are enabled by their disabilities, and are hence glad that they have it; cf Harman (2009) and Wallace (2013).

${ }^{2}$ This case is due to Williams (1981).
} 


\section{Adoption ${ }^{3}$}

A childless couple is considering adopting a son. They end up with two serious candidates, Alfred and Bob, of similar ages, backgrounds, etc. The main difference between them is their alternative prospects, should no one adopt them. Alfred belongs to a reputable and well-run orphanage; if he is not adopted, he will be referred to competent (albeit stressed and emotionally distant) foster parents, finish high school, and ultimately lead a reasonably satisfying (if often difficult) life. Bob, by contrast, belongs to a 'failing' orphanage; if he is not adopted, he will, almost inevitably, grow up in a miserable and isolating environment, preventing him from forming meaningful relationships or obtaining fulfilling employment in his adult life.

Knowing all this, our couple nonetheless adopt Alfred, because they are moved by his extremely cute smile. At the time, it's clear that this is not a sufficient reason, and that they did not act as they should have done. But as they raise Alfred and come to love him as their son, they are extremely glad that they chose as they did. After all, that decision was best for Alfred - and Alfred's welfare now has a special weight in their deliberations.

Let us say that Gauguin and our nameless couple can "retrospectively endorse" their actions. As Williams (1981) was at pains to bring out, this looks morally significant. However, it is unclear how it could be. For, as Harman (2009) and Wallace (2013) have argued, the deontic status of an action - its status as right or wrong - is independent of whether it will be susceptible to such retrospective approval. But if we deny that retrospective endorsement can affect the deontic status of the action, it is unclear how we should account for its moral significance.

In this paper, I will address this challenge by offering a new account of the significance of retrospective endorsement. My suggestion is that an agent who can retrospectively endorse an action should not feel remorse for that action and, more tentatively, should not be blamed for it. This clearly makes susceptibility to retrospective endorsement a morally significant feature of an action; ${ }^{4}$ and, I claim, it gains support from independently motivated claims about how partiality and blame interact in more straightforward situations. ${ }^{5}$

The plan for the paper is as follows. In section 1, I elaborate on the idea of retrospective endorsement and its connection to partiality; in doing this, I will

\footnotetext{
${ }^{3}$ This case is not widely discussed, but it resembles the non-identity cases introduced by Parfit (1984) and discussed by Harman (2009) and Wallace (2013). Using an example featuring adoption side-steps many of the issues specific to conception cases, such as the Non-Identity Problem or the fact that parents deciding to conceive do not (in some hard-to-pin-down sense) know at the time of the decision who they are 'benefiting'.

${ }^{4}$ Is it enough to make what you get when you can retrospectively endorse your behaviour worthy of the name "retrospective justification", which Williams uses for it (and which I use in the title)? I won't adjudicate this terminological question.

5 Wallace (2013) accounts for the significance of retrospective endorsement by maintaining that it renders all-in regret inappropriate, but denies that it has consequences for remorse and blame. I discuss the relationship between our accounts in greater detail below.
} 
respond to Wallace's (2013) objection to the idea that retrospective endorsement makes blame or remorse inappropriate. In section 2, I will offer an independent argument, based on the interaction between partiality and the appropriateness of blame in inter-personal situations, that retrospective endorsement renders remorse inappropriate. In section 3, I show how to strengthen this intermediate conclusion to establish also that it is inappropriate for other people to blame an agent for an action that she can retrospectively endorse.

\section{Section 1: Retrospective Endorsement}

It is commonplace to distinguish between 'subjective' and 'objective' deontic evaluations: one is sensitive only to the information available to the agent, the other takes into account all of the facts. We can draw a similar distinction in retrospective evaluations: when Gauguin approvingly looks back at his earlier decision, does he restrict himself to facts he could have known at the time (let us call this restricted retrospective evaluation), or does he take into account information he received only much later (let us call this unrestricted retrospective evaluation)? Both are perfectly intelligible forms of reflection; but we should be clear about which of the two we are discussing.

How we answer this question will determine which of the following two we will see as relevantly analogous to the case of Gauguin:

\section{Gauguin the Gambler}

In the midst of a debilitating mid-life crisis, Gauguin takes out his family's life-savings, and makes for Las Vegas. He places the entire savings on the $\mathrm{o}$ at the Roulette table. Against all odds, he wins, and returns a rich man. Looking back, he feels sick to his stomach about exposing himself and his family to such a huge risk. But, since it worked out, he is glad that he did it.

\section{Gauguin the Ill-Fated}

In the midst of a debilitating mid-life crisis, Gauguin abandons his family to move to Tahiti and pursue his painting hobby. When he starts painting full time, he turns out to be an extremely talented artist who loves the art-world and all that it involves. Unfortunately, however, he soon develops a rare and serious illness that prevents him from producing art, and from finding self-fulfilment in this newly discovered world. When he looks back at his decision later, he feels that the pursuit of art and self-fulfilment really is worth the kinds of sacrifices that he made. However, given that he was destined not to succeed, he wishes that he had decided to be a good husband and father instead.

If our focus is unrestricted retrospective evaluation, Gauguin is analogous to Gauguin the Gambler and unlike Gauguin the Ill-Fated; for in the first two cases, Gauguin is, knowing all that he knows now, quite glad that he acted as he did, while in the third case he is not. By contrast, if we are interested in restricted retrospective evaluation, Gauguin is analogous to Gauguin the IllFated, and unlike Gauguin the Gambler. For when Gauguin restricts himself 
to the information accessible at the time of the original decision, he must reject his actions in Gauguin the Gambler; but, since even restricted retrospective evaluation allows him to appeal to the values he's developed in the meantime, he can approve of his decision to pursue art in the other two examples. My claim, supported (I hope) by our intuitive reaction to the two modified cases, is that it is this second, restricted, kind of retrospective evaluation that is most obviously morally significant.

I will say more about this distinction shortly. But even without saying more, it should be clear that it is crucial for the plausibility of my claim that retrospective endorsement renders remorse and blame inappropriate. For, as Wallace (2013) argues by appeal to cases similar to Gauguin the Gambler, it is highly implausible that positive unrestricted retrospective evaluation should in any way prevent the agent from feeling extremely guilty or remorseful about his rash decision, or should prevent anyone for blaming him for being so irresponsible. ${ }^{6}$ This, however, has no direct bearing on the thesis that restricted retrospective endorsement can shield us from such emotions. And that is the thesis that I will defend. ${ }^{7}$

(As an aside, it is worth noting that Williams (1981), the classic defender of retrospective justification, seems - at least in certain passages - to also be concerned with something more like restricted retrospective evaluation. For Williams (1981, p. 36) identifies the agent's "standpoint of retrospective assessment" with his "sense of what is significant in life", which suggests that it includes the agent's later values, but not all the highly contingent information - about how his health would develop, or about how the Roulette wheel would land - that he might have access to at the later time. Since a "sense of what is significant in life" needs to be supplemented with some body of information if it is to yield any verdicts at all, it's then quite natural to slot in the information available when the decision was made, so that the "standpoint of retrospective assessment" gives positive verdicts on all and only those actions which receive restricted retrospective endorsement. ${ }^{8}$ )

\footnotetext{
${ }^{6}$ See especially Wallace (2013, pp. 98-104)

${ }^{7}$ The distinction does not arise for Harman's (2009) discussion, since she discussed only cases in which agents know all the relevant information from the start. But her focus on whether the agent is glad that she acted as she did suggests that her focus is also on unrestricted retrospective evaluation, since - as Gauguin the Gambler illustrates - information not available at the time of decision can clearly play a role in determining whether we should be glad we acted as we did.

${ }^{8}$ There is more evidence elsewhere in the text. For example, Williams (1981, p. p.23) writes that if Gauguin had turned out an artistic failure, he would have done the wrong thing "not just in the sense in which that platitudinously follows" but in some more interesting sense. But it does follow pretty platitudinously from the fact that Gauguin's gambit failed that it cannot receive a positive unrestricted retrospective evaluation. So Williams can't be interested in a sense of 'wrong' tied to unrestricted retrospective evaluation. Since restricting retrospective evaluation to the information available at the time is the obvious way of screening off these 'platitudinous' consequences of Gauguin's failure, this seems closer to what Williams had in mind. The unavailability of this kind of retrospective evaluation then follows not platitudinously, but rather from the fact that it's hard for art to play the intense role in Gauguin's life that it would need to for him to regard the gamble as "worth taking", when his own artistic ambitions have proven such a failure.
} 
The distinction between restricted and unrestricted retrospective evaluation more generally complicates the relationship between Wallace's (2013) account of the significance of retrospective evaluation and my own. After arguing that retrospective endorsement does not affect the appropriateness of blame or remorse, Wallace suggests that it can (at least in certain cases) affect the appropriateness of 'all-in regret'. This suggests that our accounts implement a similar strategy, both explaining the significance of retrospective endorsement by its effects on the appropriateness of certain emotional responses; but that they disagree about which particular emotions to appeal to when developing that strategy.

This story of the relationship, however, ignores the fact that I focus on restricted retrospective endorsement, while Wallace considers only unrestricted retrospective endorsement. Wallace argues that unrestricted retrospective endorsement does not, in general, render blame or remorse inappropriate; I fully agree. Having set blame and remorse aside, Wallace proposes that unrestricted retrospective endorsement may make a difference to the appropriateness of all-in regret; here too, I needn't disagree. I maintain only that there is a different form of retrospective endorsement, restricted retrospective endorsement, which is also available in cases like Gauguin and Adoption, and which does render blame and remorse inappropriate. Now, Wallace explicitly denies that the agents of Gauguin and Adoption are exempt from blame and remorse - to that extent, our views are inconsistent. But, from this new perspective, this point of disagreement does not seem a central part of Wallace's account.

Of course, showing that the thesis I want to defend isn't vulnerable to Wallace's objection - and is more generally quite consistent with much of Wallace's view - is quite different from offering positive reason to accept it. I will turn to that task shortly. For now, I will return to say a little more about how restricted retrospective endorsement works.

In restricted retrospective evaluation, the agent restricts herself to information available at the time of action. Nonetheless, the agent need not reach the same verdict as would have been appropriate at the earlier time. For the verdict depends not just on the information available, but also on the values used in the evaluation. And those values can change - as, indeed, they seem to in Gauguin, Gauguin the Ill-Fated, or Adoption. In these cases, the features that have a claim on the agent when she looks back are quite different from the features that had a claim on her when she originally made her decision. Alfred's well-being, for example, seems to have a very different claim on the parents when they look back as when they were making their original decision.

On my preferred precisification of the notion, the 'values' that matter are not the ones the agent actually happens to have, but the ones which have a genuine claim on her. (Since he identifies the relevant values with one's "sense of what

Note also that Williams (1981, p. 25) later qualifies the claim that wrongness follows from failure, to the claim that it does so only when the failure is 'intrinsic'. But the failure of my ill-fated Gauguin seems more like the kind of failure Williams calls 'extrinsic'. So Williams seems broadly sympathetic to the thought that Gauguin the Ill-Fated is more like Gauguin than Gauguin the Gambler; which is further evidence that he is after something like restricted retrospective evaluation. 
is significant in life", Williams (1981) may have the other precisification in mind; I worry that, since any action will look right given perverse enough priorities, this would make retrospective endorsement too easy to come by.) Plausibly, this makes changes in values - and hence cases in which original and retrospective evaluation yield different verdicts - relatively rare. After all, it seems that, for the most part, the same features, e.g. the well-being and rights of other people, have roughly the same claim on everybody's moral consideration.

There is, however, a special case in which it is plausible that the same features of a situation have a different (non-instrumental) claim on different people: the case of partial values, arising from relationships or personal projects. This is exactly the kind of variation we see between the initial and the retrospective perspective in a case like Gauguin or Adoption. Before they adopt Alfred, our couple have no reason to value his well-being over Bob's; but, once they have developed a relationship with Alfred, they do obtain such a reason. When Gauguin first leaves his family, he has no reason to value artistic fulfilment over other, more familiar, things such as the well-being of his family; but once art starts to play a central role in his self-conception, this (supposedly) changes. ${ }^{9}$

It's important for our purposes that the variation in values justified by partiality is variation in fundamental or non-instrumental values; for if we hold fixed both the non-instrumental values and the information, we cannot get a different verdict. Construing the variation justified by partiality as variation in non-instrumental values isn't forced on us. We could think of the change our couple go through when they adopt Alfred as merely instrumental: they always value that parents promote the welfare of their own children, whoever they might be; so, since Alfred is now their child, they now value promoting his well-being as a (constitutive) means towards promoting something that they valued all along. But, while possible, this does not seem the most natural description of what happens. ${ }^{10}$ The more intuitive construal of the case holds that, once our couple adopts Alfred, his welfare (rightly) becomes noninstrumentally valuable to them, so that they should promote it for its own sake and not just because promoting it allows them to promote the welfare of their children, whoever they might be. On the more natural construal then, the change in values justified by partiality is exactly as we need it to be.

\footnotetext{
${ }^{9}$ These cases also show that the distinction between new values and new information does not collapse even if 'values' is construed as 'values that have a genuine claim on the agent'. For while the facts which ground the new values will not typically be known to the agent beforehand, so that new values will usually come with new information, this needn't be the case. Imagine that Gauguin somehow did know that art will come to play an important part in his self-conception - I take it this would not justify him in now attaching special non-instrumental weight to artistic fulfilment (though it may increase its instrumental value as a means for ensuring his later happiness). Or imagine that I somehow know I will eventually develop a deep and important relationship with Alfred - again, this would not mean that I should already assign to his well-being the special weight that I will be entitled (even required) to assign it once we have developed that relationship. Whether new values are appropriate depends essentially on whether the events have already taken place; what information one has depends on this at most accidentally. The distinction between new values and new information thus remains in place. (Thanks to an anonymous referee for raising this worry.)

${ }^{10}$ See e.g. Keller (2013). We needn't deny that there is such a change in instrumental reasons; only that this is all that happens when our couple adopts Alfred.
} 
Changes in values justified by partiality thus allow for the possibility that an action that is assessed negatively in light of the values that have a claim on the agent at the time of action later receives restricted retrospective endorsement. This seems to be exactly what happens in cases like Gauguin and Adoption." And this construal of the cases fits well with Harman's and Wallace's claim that the possibility of retrospective endorsement makes no difference to the action's status as right or wrong. For, in assessing an action as right and wrong, we look not at how it fares relative to the partial values that have a grip on us, but how it fares relative to the partial values that have a grip on the agent; hence why I can recognize that you owe much to your children that I don't. By extension, what matters to whether the action is right or wrong is only which partial values have a grip on the agent at the time of action. That different values have a grip on a later 'time slice' of the agent, which is all that's required for restricted retrospective endorsement to be possible, looks just as irrelevant to whether the action was right or wrong as the fact that different values have a grip on other people.

However, whether an action was right or wrong is not the only thing we care about when doing ethics. We might also wonder whether the agent should feel guilt or remorse about the action; and we might wonder whether we would be right to blame him for it. It is here, I claim, that restricted retrospective endorsement starts to matter: when it is available, blame and remorse would be inappropriate. This captures something intuitive about the cases. But, more importantly, it receives independent support from reflection on how partiality and blame interact in somewhat simpler cases, in which agent and evaluator are different people - or so I will argue.

\section{Section 2: Partiality and Inappropriate Blame}

I claim that, while (restricted ${ }^{12}$ ) retrospective endorsement fails to make an action right, it does make it inappropriate to blame or feel remorse for that action. In this section, I will argue for the second part of the claim: that retrospective endorsement makes it inappropriate to feel remorse for the action; in the next section, I will discuss how to go from there to the claim that blame by other people would also be inappropriate.

I should note a reservation I have about presenting what I have to offer as an argument. Arguments are most obviously useful if their premises are, at least initially, more attractive than their conclusion - but I am not sure that this will be true of the argument I will present, even once I'm done motivating the premises. In part this is because I find the conclusion quite intuitive. But, while intuitive, I think the conclusion is also highly puzzling: it's hard to see how something like this could be true. A different way of thinking of my argument is thus as offering something like an explanation of the conclusion, of showing

\footnotetext{
${ }^{11}$ At least if we set aside difficult first-order issues, such as whether the role of art in Gauguin's later life really does make it right for him to weight artistic achievement and self-fulfilment more heavily than familial obligation - something I, at least, am sceptical about.

${ }_{12}$ Since unrestricted retrospective endorsement will play no further role, I will henceforth omit this qualification.
} 
how the conclusion can be integrated with more general principles that are at least somewhat attractive.

With this reservation noted, here is the argument:

(1) If $\mathrm{X}$ performs an action which receives a positive evaluation when assessed using Y's (partial) values and X's information at the time of action, then Y can't appropriately blame X.

(2) If (1), then if $X$ can retrospectively endorse an action (i.e. it receives a positive evaluation by his later values and his information at the time), $X$ can't appropriately blame himself for performing that action.

(C) So, if X can retrospectively endorse an action, X can't appropriately blame himself for that action; in other words, X can't appropriately feel remorse for that action. ${ }^{13}$

Premise (2) is motivated by an analogy between how I engage with my past self and how I engage with others, an analogy we appealed to earlier to support the thought that retrospective endorsement cannot affect whether an action was right or wrong. This analogy is not so strong that (2) could not possibly be rejected; but it is strong enough to justify not saying more to defend it.

The weight of the argument thus rests primarily on (1). I will defend this premise in three parts. First, I will argue that it shouldn't be rejected out of hand, clarifying in the process what I mean by "appropriate". Second, I will offer an example to support the principle. Third, I will argue that this principle harmonizes well with attractive claims about the nature of blame.

A tempting thought is that, for blame to be appropriate, it's sufficient that the action was wrong - at least if the agent also has no excuse, and the person blaming knows about both the wrongness and the lack of excuse. If this were true, (1) would be implausible. But, tempting though it is, it isn't true. If I wrong you without excuse, but later make amends and receive your (appropriate) forgiveness, it becomes inappropriate for you or others to continue blaming me for what I did. ${ }^{14}$ If I do wrong, but you are complicit in my action or currently engaged in similar behaviour, you cannot take me to task for what I'm doing. ${ }^{15}$ In these kinds of cases, the potential blamer knows that my action was wrong and that I have no excuse, but is nonetheless in no position to blame. Since there are cases of this kind, we can't just dismiss the possibility that the cases described in (1) are among them.

In showing that (1) isn't absurd, these cases also reveal something worth stating explicitly: that to blame someone is not simply to believe that what they did was wrong or blameworthy. What more is required? Some say blame requires an emotion (e.g. anger, or protest); others say it requires a desire (e.g. that the agent have acted differently, or that the agent apologize and attempt to make amends); and yet others that it requires a decision (e.g. to modify one's

\footnotetext{
${ }^{13}$ Fricker (2016, p. 177) also identifies self-blame with remorse. Gibbard (1990, p. 146), Darwall (2006, pp. 74, 112), and Williams (1993, p. 256) identify self-blame with guilt instead, but in so far as remorse is more exclusively focused on actions than guilt is, remorse seems the better choice.

${ }^{14}$ Cf Hieronymi (2001)

${ }^{15}$ Cohen (2006), Smith (2007) and Scanlon (2008, pp. 175-179)
} 
relationship with the agent). ${ }^{16}$ I won't (and needn't) take sides - I mention the different proposals only because they may help us hone in on the phenomenon in question.

It's also worth highlighting that the sense in which blaming is inappropriate in these cases is not an entirely 'extrinsic' sense: it's not (merely) that blame of this kind has bad consequences, or constitutes a separate wrong for some other reason. It may be wrong of me to blame my psychologically fragile friend for a relatively minor wrong, if I know that this will cause him to relapse into serious mental illness; but such blame needn't be misplaced in the way in which it seems to be in the cases described above. And yet the inappropriateness doesn't seem fully 'intrinsic' either: to notice it, you have to look not only at the object of the attitude, but also at some relatively far removed features of the relationship which the attitude's holder bears to that object. The blame can be inappropriate in the relevant sense, even though the agent and action at which it aims are fully blameworthy.

While not providing us with a precise account, these examples illustrate the relevant sense of "appropriate". They also show that we shouldn't reject out of hand my claim that blaming an action that receives a positive evaluation when evaluated using one's own values and the agent's information is (in the sense gestured at) inappropriate. What I need to do next, then, is to provide some positive reasons to take that claim seriously. I will begin this task by telling yet another story.

\section{Islands}

A loose acquaintance of yours, let's call him Omar, finds himself in a familiar philosopher's scenario. While spending his Sunday afternoon sailing around in his small boat, he receives the information that he can rescue either one child by taking his boat to the eastern island, or three other children by taking his boat to the western island; anyone on the island he doesn't immediately go to is sure to die.

Omar is told who the children on the islands are. The children on the western island are strangers to him; the child on the eastern island is your daughter. While Omar can just about picture her, he doesn't bear any special relationship to her (or to you). So while you would obviously head East if it was you in the boat, and would be fully justified in doing so, Omar can give no adequate reason to do the same: he is required to go West where he can save the greater number. ${ }^{17}$

Knowing all this, you are waiting helplessly on the mainland, and have almost given up hope. But you're in luck. As Omar thinks about the suffering of all the children, your daughter's suffering (the only suffering to which he can put a face) strikes him with more force,

\footnotetext{
${ }^{16}$ For accounts along such lines see, respectively, Wallace (1994), Hieronymi (2001), Wolf (2011), and Bell (2013); Sher (2006); and Scanlon (2008).

${ }^{17}$ This judgement, of course, is controversial. If you do not share it, feel free to change the example appropriately: the important feature is that Omar is required to head West, while you would be required to head East if it was you in the boat.
} 
vividness, and detail than that of the other three. ${ }^{18}$ He thus abandons the greater number and heads East to save her. As he pulls into the harbour and hands her over into your safe arms, you are, quite naturally, overwhelmed with gratitude.

What Omar does in the story is wrong: he has no adequate reason for saving this one child when doing so requires that he let three others die. Moreover, Omar has no excuse for acting as he did: he was in full control of his decision (his urge to save your daughter was not completely overwhelming!), knew all the relevant facts, etc. Still, it seems to me that it would be very strange for you to blame him for doing what he did. After all, had you been in that situation you would have been moved by exactly the same considerations to do exactly the same thing. And you would have been right to do it. How then could you, of all people, blame him for what he did? If anything, you should be grateful that he sacrificed his moral obligations for your daughter's sake.

The state that is appropriate for you to be in is, admittedly, an odd one. You can judge that Omar did wrong. You can judge that he is blameworthy: when the parent of one of the other children, a neutral onlooker, or Omar himself, takes Omar to task for his behaviour, you wouldn't object that their reactions are unjustified. But you cannot reasonably join them in blaming Omar: doing so is not your place. This is an odd situation. But, in a sense, it's nothing new: it's exactly the same combination of judgements that are called for when reacting to a wrong and unexcused action that you lack standing to blame, e.g. because you are guilty of similar wrongs.

Islands thus shows that the partial values of the potential blamer can matter to whether the blame is appropriate. Moreover, a simple variant of Islands shows that, nonetheless, the information of the agent needs to be held fixed. For imagine instead that, while Omar is told that he can reach either island if he heads there immediately, you know all along that the eastern island (the one with your daughter on it) is too far. It seems clear that, if you can't blame Omar for saving your daughter in Islands, you can't blame him for trying to save her in this variant either. This suggests that what makes the blame inappropriate is not that you are, overall, happy about his decision, but rather that his action receives a positive evaluation from the combination of your values and his information. In other words, it suggests that (1) really is the lesson to draw from the example. ${ }^{19}$

Of course, Islands is just an example - and an odd one at that. So it's worth emphasizing that the verdict in Islands, and (1) more generally, also meshes with theoretically attractive claims about blame. Sher maintains that blaming involves a backward-looking desire "that the person in question not have

\footnotetext{
${ }^{18}$ Psychologically, this is not overly unrealistic: 'identifiable victims' often weigh more heavily in people's intuitive deliberations than victims who are characterized only abstractly or statistically.

${ }^{19}$ In Islands and its variant, the reasons motivating $X$ to perform the action (namely: your daughter's well-being) are the very same as the reasons that account for the positive evaluation when we use Y's values. Perhaps this is essential to the intuition (though I'm inclined to think that, once we distinguish blame for an action and blame for a motive, it is not); if so the case really supports a more restricted version of (1), which would, however, do just as well for my purposes.
} 
performed his past bad act" (Sher, 2006, p. 112); but it would clearly be inappropriate for you to have such a desire about Omar's saving of your daughter. More generally, it seems that if your partial values support some action, it would be odd for you to desire that the agent have opted for a different one. (Unless, of course, you have additional knowledge about the consequences; but such knowledge needs, at any rate, to be screened off, if Sher's suggestion is to be compatible with the obvious appropriateness of blame in cases like Gauguin the Gambler). So Sher's view supports (1) quite generally.

It is also natural to think that blame involves an element of protest. ${ }^{20}$ But it would clearly be inappropriate for you to protest Omar's saving of your daughter. More generally, if some action is supported by your partial values, and is the thing you would (rightly) do in those circumstances and given the same information, then it seems odd of you to protest it. So the protest element also supports (1) quite generally.

Finally, it's plausible that A can appropriately blame B for an action only if A's demand that $\mathrm{B}$ not perform that action would also have been appropriate. ${ }^{21}$ (Or rather, since we need to control for the fact that A's demand might pass on additional information, A can appropriately blame B only if A could, knowing all and only what B knew at the time, have demanded that B not perform the action.) Yet, again, there seems something deeply suspect with your demand that Omar leave your daughter to die and save the three other children instead. More generally, if some action is supported by your partial values, if it's the thing that you would want the agent to do if you knew only what they know, it would surely be unreasonable for you to demand that the agent not do that thing. So the connection to demands also supports (1) quite generally.

These theoretical considerations provide further evidence for my judgements about Islands and for (1) - but because they (at best) pass on the explanatory buck, they do little to explain why (1) would be true. This is not a gap I can fill. But my sense is that (1) is true because to blame in a situation of this kind requires stepping away from one's partial values in a way that we regard as inappropriate. To blame Omar for saving your daughter (or for trying to save her) would be to betray her, or your relationship with her. And I get exactly the same sense when I imagine being one of the parents in Adoption, facing someone who demands that I feel remorse for my decision. I can, to some extent, see where they are coming from. But to feel remorse over opting for Alfred would require me to reject the value I (rightly) place in him now. For this reason their request ultimately strikes me as inappropriate. This sense is, I think, further evidence that the same phenomenon underlies both (1) and the claim that retrospective endorsement renders remorse inappropriate. ${ }^{22}$

\footnotetext{
${ }^{20}$ Cf Hieronymi (2001), Talbert (2012), Smith (2013)

${ }^{21}$ See e.g. Strawson (1962, p. 90) and Darwall (2006, p. 81).

${ }^{22}$ This helps with a worry that there is a tension between my defense of (1) and my endorsement of (2). For in defending (1), I appeal to cases where blame is inappropriate because the person blaming is complicit in the action in question, or engaged in similar ones. But these are cases in which the analogy supporting (2) breaks down: I am (trivially) complicit in all of my own actions, yet this does not render it inappropriate ever to blame myself. Why, then, think that the analogy remains intact in the cases I'm
} 
This completes my argument for (1), and hence for my claim that retrospective endorsement really does render remorse inappropriate. I will readily admit that it is not a decisive argument - everything in this terrain is slightly murky. Still, the argument casts some light on and adds some plausibility to (C) - even if, as mentioned earlier, it does so only by showing how (C) might be integrated with more general thoughts in moral psychology. So I will move on, and explain how (C) can be extended to yield even stronger conclusions about the effects of retrospective endorsement.

\section{Section 3: Protection from Blame}

In the previous section, I argued that (restricted) retrospective endorsement makes it inappropriate for the agent to feel remorse about his or her action. In this section, I sketch a way to extend this conclusion to argue that retrospective endorsement also makes it inappropriate for others to blame the agent for what he or she did. If right, this makes retrospective endorsement even more significant than the intermediate conclusion of section 2 already suggested.

My argument for the claim is simple. It appeals to the following principle:

(3) If X can't appropriately feel remorse for an action, then others can't appropriately blame $\mathrm{X}$ for that action.

The conclusion then follows immediately from the intermediate (C).

Why believe (3)? Not because blame and remorse are responses to the same feature of a situation, such as its wrongness or its blameworthiness. That can't be the reason to accept (3) because it ignores the very fact I've been emphasizing, namely that whether blame (and remorse) are appropriate depends not just on the features of the situation, but also on the blamer's relationship to that situation.

But there is a different reason to accept (3). It's natural to think that blame and related kinds of moral reproach 'call out' for remorse from the one being reproached. ${ }^{23}$ Clearly, such a call will be inappropriate if the thing it calls for is itself inappropriate. ${ }^{24}$ So (3) follows from this natural thought about blame.

To help push the intuition, imagine being one of the parents in Adoption, and pretend that you're convinced by my argument that it would not do for you to feel remorse about what you did. Now imagine that some uninvolved third party confronts you about your decision to adopt Alfred. You explain that while

concerned with? My only answer is that - as I say above - it just seems to be: blaming myself for an action that I can now endorse seems just as problematic, and for exactly the same reason, as blaming you for something I endorse. This just looks like a way in which issues about hypocrisy, and issues arising from partiality, behave slightly differently. (Thanks to an audience member at the 2015 meeting of the British Society for Ethical Theory for raising this concern.)

${ }^{23}$ See especially Fricker (2016); Gibbard (1990, p. 294), Darwall (2006, pp. 112, 271), and Shoemaker (2007, p. 91) endorse analogous claims about the connection between blame and guilt, but again remorse seems the more precise candidate.

${ }^{24}$ Of course, calling out for remorse may still be the best thing to do all things considered, e.g. because it has various positive consequences. 
you appreciate you didn't have good reasons for doing what you did, and hence did do wrong, you did what was best for Alfred and this makes it inappropriate to feel remorse about your decision. Unmoved by this response, your interlocutor continues his reproaches. Does he not, at that point, become unreasonable? In light of your explanation, what could he possibly still be asking of you?

(3) thus has a good deal of plausibility. However, some may feel that it is too strong. For suppose that instead of an uninvolved third party, it is Bob himself who reproaches you for your decision. In that case, it may seem less attractive to dismiss the complaint as inappropriate: you may have the right to feel reconciled with what happened, but Bob also seems to have the right not to be. One could take this as reason to weaken (3) to something like

(3') If X can't appropriately feel remorse for an action, then third parties can't appropriately blame $\mathrm{X}$ for that action.

Such a weakening may even receive independent support from 'dirty hands' examples where some want to say that victims can legitimately blame an action which was, all things considered, the right thing to do. ${ }^{25}$ The resulting principle would still allow us to conclude that retrospective endorsement makes it inappropriate for third parties - but not for victims - to blame the agent. Interestingly enough, some defenders of retrospective justification, such as Williams (1981, pp. 23-24) or Korsgaard (1997, p. 26), explicitly restrict their hopes in exactly this way.

The retreat to (3)), however, also raises issues of its own. ${ }^{26}$ What is Bob doing, if he isn't calling out for remorse? And if Bob can do that, why can't other people? More generally, how can this differential treatment between victims and third parties be reconciled with the idea that third party blame is often a matter of taking up the victim's case?

So we may be better off holding our ground and defending the unrestricted (3). In doing so, we can allow that Bob may be entitled to all kinds of things - to be upset at what happened, to identify me as the cause of his misfortune, perhaps even to demand that I compensate him. We can also allow that it would be quite understandable for Bob to, in the grip of his justified emotional reactions, overshoot the mark and blame me, failing to appreciate how my situation has changed and thus expecting me to feel remorse over what I did. We would merely say that - understandable though it is - it is not ultimately a justified reaction.

I will not attempt a definitive evaluation of the terrain here. But, given the above, it does seem plausible that either (3) itself, or something in its vicinity, is true. And as long as that is right, the protection against (appropriate) remorse created by retrospective endorsement will percolate out to also provide some form of protection against (appropriate) blame.

\footnotetext{
${ }^{25}$ See e.g. Williams (1981, pp. 37, 59-6o)

${ }^{26}$ Thanks to an anonymous referee for discussion.
} 


\section{Section 4: Conclusion}

This completes my defence of the moral significance of the kind of retrospective 'change in evaluation' that we find in cases like Gauguin and Adoption. I have identified a feature of such cases (they are cases in which the action is subject to restricted retrospective endorsement), and have argued that this feature means that, even though the action was wrong and unexcused, the agent should not feel remorse for their decision; arguably it even means that others should not blame them for it.

In defending this role for retrospective endorsement, I have defended something that fits a natural definition of "moral luck": cases in which morally significant features of some actions, e.g. whether they are subject to appropriate remorse and blame at a later time, can depend on factors beyond the agent's knowledge or control. After all, it's not always predictable or entirely up to us whether a project or a person comes to take the kind of role in our life which justifies us in treating them with partiality. Defending such moral luck was, of course, Williams's (1981) primary ambition in drawing our attention to cases like Gauguin.

This vindication of Williams's primary ambition may, however, turn out to be a pyrrhic one. For it seems to me that, in defending the phenomenon, I have also rendered it less threatening or puzzling than Williams would have wanted it to be. After all, whether my actions are subject to appropriate remorse and blame at a later time can also depend on whether I will be forgiven, and (at least in the case of blame) on whether those around then will have the standing to hold me to account. And these, too, are factors about which I may have limited knowledge or control; yet, their existence is hardly inconsistent with the moral system we have internalized. Perhaps there is something that makes the protection from remorse and blame generated by retrospective endorsement more threatening to moral theory than these other cases; but, if so, we have yet to articulate what it is. ${ }^{27}$

\section{Bibliography}

Bell, M. (2013). Hard Feelings: The Moral Psychology of Contempt. Oxford: Oxford UP.

Cohen, G. (2006). Casting the First Stone: Who can, and who can't, condemn the terrorists? Royal Institute of Philosophy Supplement, 58, 113-136.

\footnotetext{
${ }^{27}$ I am grateful to Arden Ali, Tom Dougherty, Caspar Hare, Richard Holton, Abby Jacques, Kieran Setiya, Paulina Sliwa, Jack Spencer, Brad Skow, Josh Thorpe, two anonymous referees, and audiences at MIT, the 2015 University of Toronto Graduate Conference in Philosophy (especially my commentator Christopher Bantle), and the 2015 meeting of the British Society for Ethical Theory for extremely helpful discussions on these issues. I am particularly grateful to Julia Markovits and Brendan de Kenessey, without whose insights and encouragement this paper would never have seen the light of day.
} 
Darwall, S. (2006). The Second Person Standpoint. Cambridge MA: Harvard UP.

Fricker, M. (2016). What is the Point of Blame? Noûs, 50, 165-183.

Gibbard, A. (1990). Wise Choices, Apt Feelings. Cambridge MA: Harvard UP.

Harman, E. (2009). "I'll be Glad I did it Reasoning" and the Significance of Future Desires. Philosophical Perspectives, 23, 177-199.

Hieronymi, P. (2001). Articulating an Uncompromising Forgiveness. Philosophy and Phenomenological Research, 62, 115-148.

Keller, S. (2013). Partiality. Oxford: Oxford UP.

Korsgaard, C. (1997). Taking the Law into our own Hands. In A. Reath, B. Herman, \& C. Korsgaard, Reclaiming the History of Philosophy: Essays for John Rawls. Cambridge: Cambridge UP.

Parfit, D. (1984). Reasons and Persons. Oxford: Oxford UP.

Scanlon, T. (2008). Moral Dimensions: Permissibility, Meaning, Blame. Cambridge MA: Harvard UP.

Sher, G. (2006). In Praise of Blame. Oxford: Oxford UP.

Shoemaker, D. (2007). Moral Address, Moral Responsibility, and the Boundaries of the Moral Community. Ethics, 118, 70-108.

Smith, A. (2007). On Being Responsible and Holding Responsible. Journal of Ethics, 11, 465-484.

Smith, A. (2013). Moral Blame and Moral Protest. In D. J. Coates, \& N. Togazzini, Blame: its Nature and Norms. Oxford: Oxford UP.

Strawson, P. (1962). Freedom and Resentment. Proceedings of the British Academy, 48, 1-25.

Talbert, M. (2012). Moral Competence, Moral Blame, and Protest. Journal of Ethics, 16, 89-109.

Wallace, R. J. (1994). Responsibility and the Moral Sentiments. Cambridge MA: Harvard UP.

Wallace, R. J. (2013). The View from Here. Oxford: Oxford UP.

Williams, B. (1981). Moral Luck. Cambridge: Cambridge UP.

Williams, B. (1993). Postscript. In D. Statman, Moral Luck. Albany NY: State University of New York Press.

Wolf, S. (2011). Blame, Italian Style. In R. Wallace, R. Kumar, \& S. Freeman, Reasons and Recognition: Essays on the Philosophy of T.M. Scanlon. Oxford: Oxford UP. 